\title{
Highly Organic Soil Stabilization by Using Sugarcane Bagasse Ash (SCBA)
}

\author{
Mohd Khaidir Abu Talib ${ }^{1, *}$, and Yasufuku Noriyuki $^{2}$ \\ ${ }^{1}$ Department of Infrastructure and Geomatic Engineering, Faculty of Civil and Environmental \\ Engineering, Universiti Tun Hussein Onn Malaysia, 86400 Batu Pahat, Johor, Malaysia \\ ${ }^{2}$ Geotechnical Engineering Laboratory, Department of Civil Engineering, Faculty of Engineering, \\ Kyushu University, 744 Motooka, Nishu-ku 819-0395 Fukuoka, Japan
}

\begin{abstract}
The study objective is to develop alternative binders that are environment friendly by utilizing sugarcane bagasse ash (SCBA) in the organic soil stabilization. Together with SCBA, Ordinary Portland Cement (OPC), calcium chloride $\left(\mathrm{CaCl}_{2}\right)$ and silica sand (K7) were used as additives to stabilize the peat. In obtaining the optimal mix design, specimens of stabilized peat were tested in unconfined compression. It was found that stabilized peat comprising 20\% and 5\% (PCB1-20 and PCB2-5) partial replacement of OPC with SCBA 1 and SCBA 2 attain the maximum unconfined compressive strength (UCS) and discovered greater than UCS of peat-cement (PC) specimen. At the optimal mix design, the UCS of the stabilized peat specimens increased with increasing of curing time, preloading rate, OPC and K7 dosage. For PCB1-20 mixture, inclusion of a minimum OPC of $300 \mathrm{~kg} / \mathrm{m}^{3}$ and $\mathrm{K} 7$ of $500 \mathrm{~kg} / \mathrm{m}^{3}$ along with curing under $20 \mathrm{kPa}$ pressure is recommendable for the peat stabilization to be effective. However for PCB2-5, it suggested to use more OPC and K7 dosage or alternatively increase the preloading during curing to $40 \mathrm{kPa}$ in order to achieve target UCS. It can be concluded that SCBA 1 has better quality than SCBA 2 in peat stabilization especially the contribution made by its fine particle size.
\end{abstract}

\section{Introduction}

As a result of high organic content, presence of humic acid and less solid particles in peat soil, the proper hydration of stabilized peat could be hindered [1-5]. That means the large amount of cement is needed in order to neutralize the acids or otherwise the process of the soil stabilization remains retarded. However, adding a large quantity of cement into the peat is absolutely an unfriendly and uneconomical solution to peat ground improvement considering the fact that the peat ground is covers a wide area, the rising cost of cement and its transportation to the site [6]. Cement is responsible for about $5 \%-8 \%$ of global carbon oxide, $\mathrm{CO}_{2}$ emissions and expected to grow 0.8 to $1.2 \%$ per year until may reach 4.4 billion tonnes of productions in 2050 [7].

* Corresponding author: khaidir@uthm.edu.my 
The productions of sugarcane is world number one commodities with amount around 1.9 billion tonnes in 2013 [8] and produced a lot of bagasse. Bagasse is the residue left after the crushing of sugar cane for juice extraction and on average about $32 \%$ of bagasse is produced from every tonne of sugar cane. Bagasse is burnt to generate power required for diverse activities in the factory and finally leave the bagasse ash as a waste. Increasing concern of disposal of bagasse residual creates interest to explore the potential application of this material. Increasing concern of disposal of bagasse residual creates interest to explore the potential application of this material [9]. The sugarcane industry is still seeking solutions to dispose of the wastes generated by the sugar and alcohol production processes. This ash is used as fertilizer in the plantations, but it does not have adequate mineral nutrients for this purpose [10]. Currently, there is no evidence in the current literature of its use in soil stabilization especially for organic soil.

Consequently, it could be something beneficial to develop alternative binders that are environment friendly and contribute towards sustainable management. The utilization of SCBA in the stabilization of peat soil can be an interesting idea and appears to be promising alternative when considering issues of energy consumption and pollution. The objective of this research works is to evaluate effectiveness factors of two type of SCBA inclusion in peat stabilization on its strength.

\section{Experimental studies}

The materials that had been used in this study are peat soil, Ordinary Portland Cement (OPC), calcium chloride $\left(\mathrm{CaCl}_{2}\right)$, silica sand and Sugarcane Bagasse Ash (SCBA). Peat samples were obtained from Sapporo in the Hokkaido region, Japan. Two types of SCBA samples namely SCBA 1 and SCBA 2 were directly brought from Shinko Sugar Industry Co., Ltd, Kagoshima prefecture in Kyushu, Japan. The well graded silica sand so called K7 type was prepared as a filler to increase the solid particles and enhance the filling effect of the stabilized peat. The entire laboratory test regulation and standards that had been implemented in this study was adopted from American Society for Testing and Materials (ASTM) [11] standards. The UCS tests were conducted at all samples with the aim to clarify the stabilized peat strength improvement. The whole mix designs of stabilized peat for laboratory testing are shown in Table 1. The mix designs of stabilized peat were formulated in term of binder composition and dosage. Each binder dosage was determined based on the bulk density of peat at its average natural water content. After all materials were mixed with untreated peat by using a laboratory mixer at approximately 10 minutes, the stabilized specimens were place into the mould by filling and tamping in about five equal layers. Each cylinder mould has a size of $60 \mathrm{~mm}$ internal diameter and $300 \mathrm{~mm}$ height. The samples then immersed in water for curing at identified duration under initial pressure by using air pressure to simulate the surcharge pressure on the stabilized soil at site. After curing durations complete, the cylinder tube is removed and the test specimen is cut to the required size for testing. Towards the degree of improvement evaluation, the established parameters of the stabilized soil should be compared to those of untreated peat.

\section{Results and discussions}

\subsection{Materials properties}

Basic properties of the untreated peat and the percentages of chemical compounds of the materials were exposes in Table 2 . With the intention of ensure the reliability of results in Table 2, the basic properties ranges for typical Hokkaido peat were collected from 
published data [12-14] and had been used for guidance purpose. In this study, it can be understood that the peat has fiber content between $33 \%$ and $67 \%$, ash content exceed $15 \%$ and $\mathrm{pH}$ value at 5.46. Therefore, this peat can be classified as hemic peat with high ash content and moderate acidic [11]. With the high water content, liquid limit, void ratio, compression index accompanied by low shear strength, the studied peat demonstrated the high compressibility and instability characteristics.

Table 1. Laboratory mix designs

\begin{tabular}{|c|c|c|c|c|c|c|}
\hline No. test & $\begin{array}{l}\text { Type of } \\
\text { test }\end{array}$ & $\begin{array}{c}\text { Curing } \\
\text { duration } \\
\text { (days) }\end{array}$ & $\begin{array}{c}\text { Initial } \\
\text { pressure } \\
\text { (kPa) }\end{array}$ & $\begin{array}{c}\text { Cement } \\
\text { dos age } \\
\left(\mathrm{kg} / \mathrm{m}^{3}\right)\end{array}$ & $\begin{array}{c}\text { Silica s and } \\
\text { dos age } \\
\left(\mathrm{kg} / \mathrm{m}^{3}\right)\end{array}$ & $\begin{array}{c}\text { Binder compositions } @ \\
\text { acronym }\end{array}$ \\
\hline 1 & \multirow{5}{*}{ 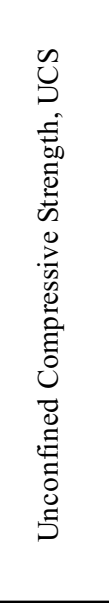 } & 7 & 20 & 300 & 500 & $\begin{array}{c}\text { 100\% OPC @PC } \\
\text { 95\%OPC:5\%SCBA @ PCB5 } \\
\text { 90\%OPC:10\%SCBA @ PCB10 } \\
\text { 85\%OPC:15\%SCBA @ PCB15 } \\
\text { 80\%OPC:20\%SCBA @ PCB20 } \\
\text { 75\%OPC:25\%SCBA @ PCB25 }\end{array}$ \\
\hline 2 & & $\begin{array}{c}7,14,21, \\
28,60\end{array}$ & 20 & 300 & 500 & \multirow{4}{*}{$\begin{array}{l}\text { The optimum binder } \\
\text { composition from test (1) }\end{array}$} \\
\hline 3 & & 7 & $\begin{array}{c}0,20,40 \\
60,80,100\end{array}$ & 300 & 500 & \\
\hline 4 & & 7 & 20 & $\begin{array}{c}100,150,200 \\
250,300\end{array}$ & 500 & \\
\hline 5 & & 7 & 20 & 300 & $\begin{array}{c}0,100,200 \\
300,400,500\end{array}$ & \\
\hline
\end{tabular}

Table 2. Peat soil basic properties

\begin{tabular}{|l|c|c|}
\hline \multicolumn{1}{|c|}{ Untreated Hok kaido peat soil properties } & Res ults & $\begin{array}{c}\text { Publis hed } \\
\text { data }\end{array}$ \\
\hline Natural water content, \% & 580 & $115-1570$ \\
\hline Ash content, \% & 16.79 & $2-80$ \\
\hline Organic content , \% & 83.21 & $20-98$ \\
\hline Bulk unit weight $\left(\mathrm{kN} / \mathrm{m}^{3}\right)$ & 10.57 & $7.1-19.7$ \\
\hline Specific gravity, Gs & 1.67 & $1.04-2.63$ \\
\hline Fiber content, \% & 43 & $42-86.9$ \\
\hline Acidity, $\mathrm{pH}$ & 5.46 & - \\
\hline Liquid Limit, \% & 375 & - \\
\hline Void ratio, $e_{o}$ & 9.65 & $2-21$ \\
\hline Compression Index, $\mathrm{C}_{\mathrm{c}}$ & 4.89 & $0.3-14$ \\
\hline Precons oilidation pres sure, $\sigma^{\prime} \mathrm{c}(\mathrm{kPa})$ & 25 & - \\
\hline Unconfined compressive strength, $\mathrm{qu}_{\mathrm{u}}(\mathrm{kPa})$ & 13.6 & $5-40$ \\
\hline
\end{tabular}

The particle size distribution of the peat and other materials are tabulated in Fig. 1. The particle size distribution curves for the soils were obtained by dry sieve analysis. In addition to the normal sieve test method, the finer fraction was analyzed using a laser diffraction method (SALD). As can be seen, Hokkaido peat consists of $90 \%$ of the soil that 
finer than $4.75 \mathrm{~mm}$, and about $2 \%$ is finer than $75 \mu \mathrm{m}$. Most of $\mathrm{K} 7$ particles sizes are 0.05 to $0.3 \mathrm{~mm}$ in range. The SCBA 1 and SCBA 2 particles consist about $80 \%$ and $15 \%$ finer than $0.045 \mathrm{~mm}$ (passing No. 325 sieve) respectively. This result also indicates that SCBA 1 is finer than SCBA 2 with average particle size are $\left(\mathrm{D}_{50}\right)$ around 18 and $260 \mu \mathrm{m}$ individually.

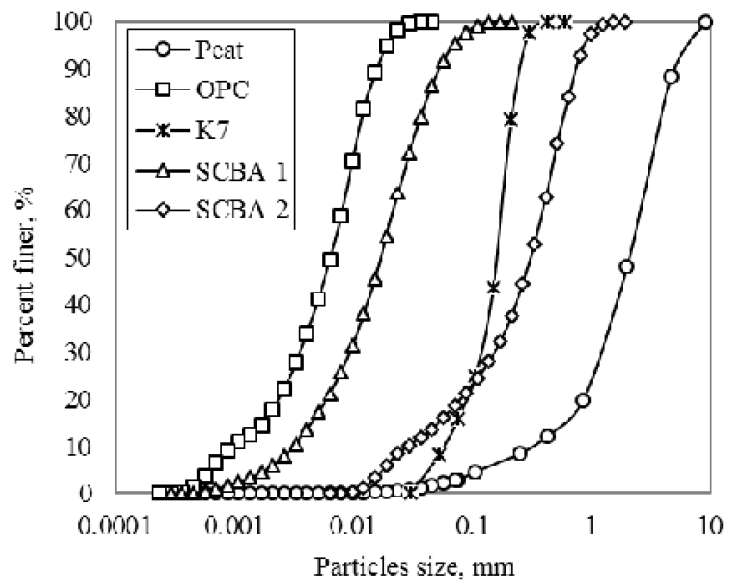

Fig. 1. Particle size distribution of peat and materials

\subsection{Effect of partial replacement of OPC with SCBA on the strength characteristic}

Fig. 2 shows the experimental results of the effect of both SCBA percentage replacements on the UCS of the stabilized peat. An optimal UCS of the stabilized soil was evaluated based on the results of UCS on the specimens of stabilized peat with partial replacement of the cement with SCBA that varies from $5 \%$ to $25 \%$ as shown in Table 1 . The UCS ratio, $\mathrm{q}_{\mathrm{u}} / \mathrm{q}_{\mathrm{o}}$ means the ratio between unstabilized and stabilized peat compressive strength. It can be detected that the test specimen with $20 \%$ partial replacement of OPC with SCBA 1 (PCB1-20) has the highest UCS of $387 \mathrm{kPa}$ and was discovered to be about 30 times better than unstabilized peat (P) and approximately 1.2 times greater than UCS of cement stabilized (PC) specimen. On the other hand, SCBA 2 mixture achieves the optimum at only 5\% of cement replacement (PCB2-5) and recorded slight increment compared to PC specimen. As stated by ASTM-D4609 [15], an increase in UCS of $345 \mathrm{kPa}$ (adopted as minimum UCS target in this study) or more must be reached for a treatment to be considered effective.

The main reasons why PC mixture gave lower strength than optimum mixture of SCBA 1 and SCBA 2 are because peat soil consists of high organic content and less solid particles. Organic soils can retard or prevent the proper hydration of cement in soil mixtures and become insufficient to provide the required function for peat stabilization. Matched to clay and silt, peat has a considerably lower content of clay particles that can enter into secondary pozzolanic reactions $[1,2]$. The combination of humic acid with calcium ions produced in cement hydration makes it difficult for the calcium crystallization, which is responsible for the increase of peat soil-cement mixture strength to take place [5]. The fact that the test specimen of PCB1-20 and PCB2-5 has the UCS may be explained by a condition whereby it has achieved an optimal effect of hydration reaction. By means of the inclusion of pozzolan such as SCBA in the soil-cement mixture, hydration of cement is accelerated when the pozzolan reacts with calcium hydroxide and water to form more secondary calcium silicate hydrate $(\mathrm{CSH})$ along with calcium alumina silicate hydrates (CASH). This 
is probable because the pozzolan which contains extra silica and alumina that activated by cement is able to counterbalance the acid and create an alkaline atmosphere that boosts the secondary pozzolanic reaction within the cemented soil. Additional $\mathrm{CSH}$ and $\mathrm{CASH}$ densify the stabilized peat, thereby further enhancing its strength [6]. Frequently, the pozzolanic effect depends not only on the pozzolanic reaction but also on the physical or filler effect of the smaller particles in the mixture [16]. The positive result indicates that the optimal mix design can be effectively applied to stabilize the peat in such a way that the fine particles of pozzolan fill up the pore spaces of the cemented soil, thus closely packing, reinforcing and strengthening its matrix as the hydration and pozzolanic products are formed during cement hydrolysis [17]. In this assessment, it can be understood that SCBA 1 has better quality than SCBA 2 in peat stabilization especially the contribution made by its fine particle size.

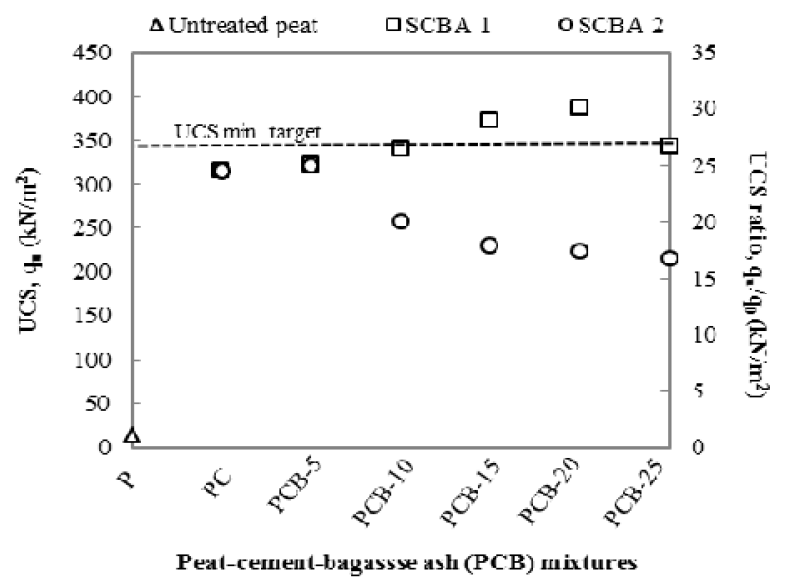

Fig. 2. Effect of SCBA percentage replacement on the UCS of the stabilized peat

\subsection{Effect of curing duration and preloading on the optimum PCB mixtures}

It can be observed from Fig. 3(a) that the UCS of both optimum PCB mixture specimens increased while increasing the duration of curing. The UCS of test specimens increased progressively at the curing time in water of 7, 14, 21, 28 and 60 days. It is evident from the findings that the duration of curing influenced the UCS of test specimens. The minimum UCS achieved at 7 and 21 days at the respective PCB1-20 and PCB2-5. Both optimum PCB mixtures show the slow increment compare to PC mixtures and overall PCB 1 mixtures demonstrates the higher positive results. This results shows the good agreement with the fact that cement hydration (PC mixtures) is normally rapid and effective at first month but almost stop or complete after that duration while pozzolan reaction can be occurred continuously until several month or even years $[6,18,19]$. Therefore it is plainly indicate that the quality of selected SCBA is very important and should be prudently examined in order to get long term strength gain.

The results in Fig. 3(b) shows the positive and linear improvement when the initial loading during curing rise. It observed that preloading gave the significant increment even only subjected the pressure as small as $20 \mathrm{kpa}$. For PCB2-5, it is suggested to use at least $40 \mathrm{kPa}$ preloading to the aim of minimum strength. The strength of stabilized peat is pronouncedly affected by the application of initial load shortly after mixing with binder. Particularly in stabilizing peat, preloading in the field has been regarded necessary in order to create a more homogeneous stabilized mass of peat. Besides that, preloading provides a trafficable bed for the continuous stabilization of adjacent areas, thereby considerably 
improve the strength of stabilized peat. The void spaces between the binder grains and the solid soil particles in peat would be reduced by the compression that occurs under preloading. [3].
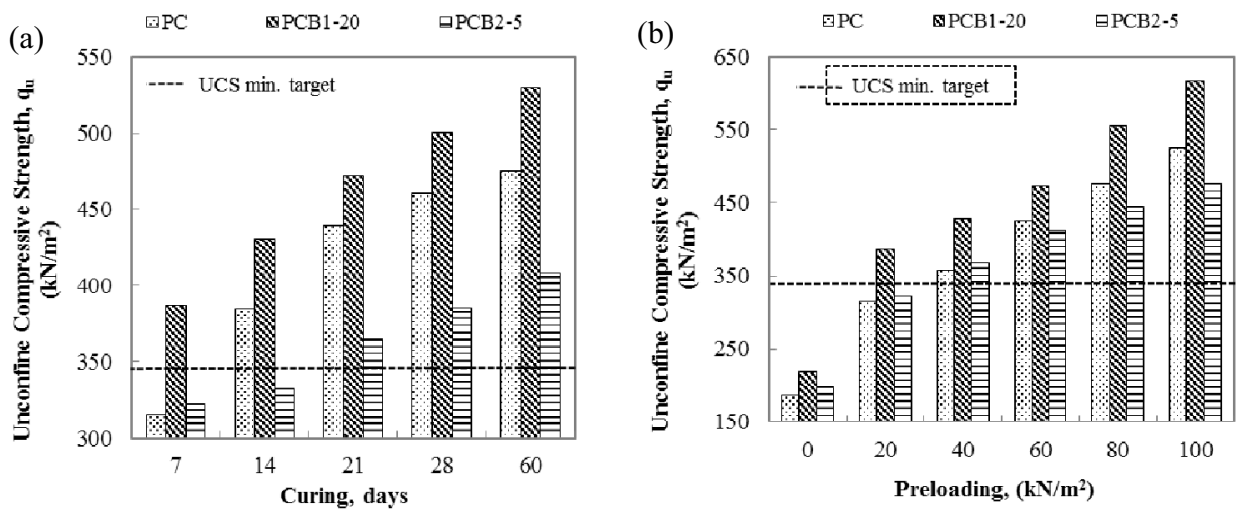

Fig. 3. Effect of optimum PCB mixture on the UCS at various (a) curing durations, and (b) preloading

\subsection{Effect of OPC and K7 dosage on the optimum PCB mixtures}

Fig. 4(a) and Fig. 4(b) show the results of the effect of the OPC and K7 dosage to the UCS of optimum PCB mixtures. It can be seen that strength gain gradually increases with OPC dosage and it's more obvious after the amount exceed $250 \mathrm{~kg} / \mathrm{m}^{3}$. It is revealed that at satisfactory OPC quantity, the acid in the peat could be neutralized. This also imply that below the threshold binder dosage, stabilization of the peat remains hindered due to insufficient binder to induce cement hydration and pozzolanic reactions in the test specimens. There was a progressive increment of the UCS when the dosage of K7 of the test specimens increases. This suggests that well graded $\mathrm{K} 7$ had a positive effect on the development of the UCS in such a way that it increased the density and reduced the void of the test specimens. Because $\mathrm{K} 7$ is chemically inert, it did not take part in the cement hydration process. However, it provided solid particles for the binder to bind and form a load bearing stabilized soil. For PCB1-20 mixture, inclusion of a minimum OPC dosage of $300 \mathrm{~kg} / \mathrm{m}^{3}$ and $\mathrm{K} 7$ dosage of $500 \mathrm{~kg} / \mathrm{m}^{3}$ along with curing under $20 \mathrm{kPa}$ pressure is recommendable for the peat stabilization to be effective. However for PCB2-5 mixture, it suggested to use more OPC and K7 dosage to achieve minimum strength target.
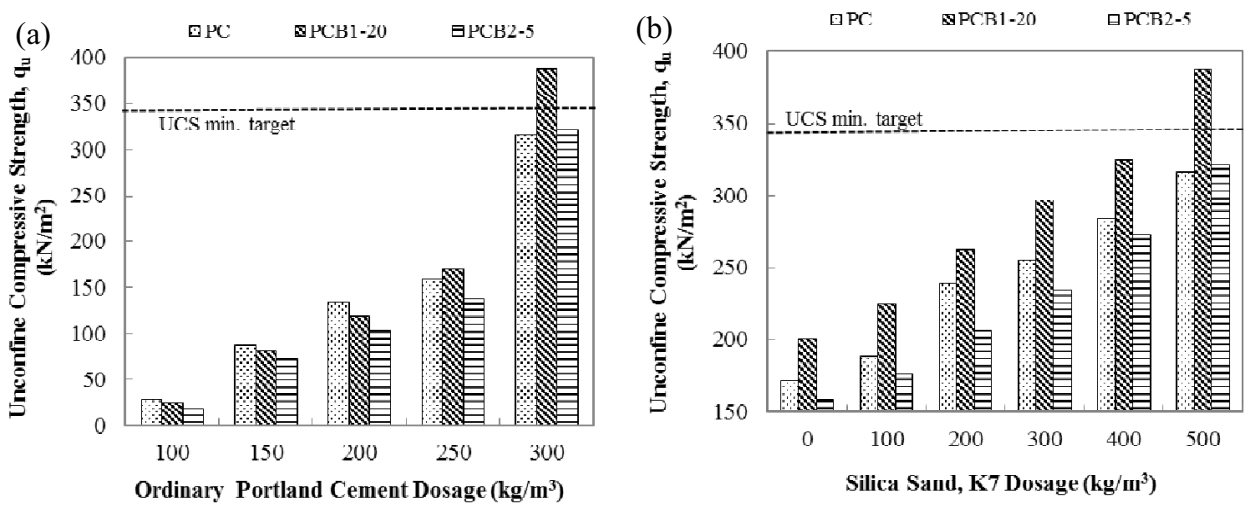

Fig. 4. Effect of optimum PCB mixture on the UCS at various (a) OPC dosage, and (b) K7 dosage 


\section{Conclusions}

Highly organic or peat soil stabilization by utilizing the SCBA waste as a partial cement replacement has been studied. It can be summarized from the experimental outcomes that SCBA has made a substantial effect on the strength properties of the stabilized peat. Based on the results of the laboratory investigation, the following concluding comments are made:

i) Untreated peat in this study can be classified as hemic peat with high ash content and moderate acidic. With the high water content, high liquid limit and low shear strength, this soil demonstrated the high compressibility and instability characteristics.

ii) It was observed that PCB1-20 has the highest UCS of $387 \mathrm{kPa}$ and was discovered to be about 30 times better than unstabilized peat $(\mathrm{P})$ and approximately 1.2 times greater than UCS of PC mixture. On the other hand, SCBA 2 mixture achieves the optimum at only 5\% of cement replacement (PCB2-5) and recorded slight increment compared to PC specimen.

iii) The UCS of the stabilized peat specimens at the optimal mix design increased significantly with increasing of curing time, preloading during curing, OPC dosage and $\mathrm{K} 7$ dosage.

iv) For PCB1-20 mixture, inclusion of a minimum OPC dosage of $300 \mathrm{~kg} / \mathrm{m}^{3}$ and $\mathrm{K} 7$ dosage of $500 \mathrm{~kg} / \mathrm{m}^{3}$ along with curing under $20 \mathrm{kPa}$ pressure is recommendable for the peat stabilization to be effective. However for PCB2-5 mixture, it suggested to use more $\mathrm{OPC}$ and $\mathrm{K} 7$ dosage or alternatively increase the preloading during curing to $40 \mathrm{kPa}$ in order to achieve minimum strength target.

v) It can be concluded that SCBA 1 has better quality than SCBA 2 in peat stabilization especially the contribution made by its fine particle size. The quality of selected SCBA is very important and should be prudently examined in order to get long term strength gain.

Overall, it is suggested that the obtained optimum mix design can be applied to stabilize the peat layer in order to support road embankment for rural or agricultural road network.

\section{References}

[1] S. Hebib, E.R. Farrells, Some experiences on the stabilization of Irish peats of paper, Canadian Geotechnical Journal, 40(1), 107-120 (2003)

[2] M. Janz and S.E. Johansson, The function of different binding agents in deep stabilization of report, Swedish Deep Stabilization Research Center, (2002)

[3] H. Ahnberg, Strength of stabilised soils - A laboratory study on clays and organic soils stabilised with different types of binder of report, Swedish Deep Stabilization Research Centre, (2006)

[4] K. Axelsson, S.E. Johansson, R. Anderson, Stabilization of organic soils by cement and puzzolanic reactions- feasibility study of report, Swedish Deep Stabilization Research Centre, (2002)

[5] H. Chen, Q. Wangs, The behaviour of organic matter in the process of soft soil stabilization using cement of paper, Bulletin of Engineering Geology and the Environment, 65(4), 445-448 (2006)

[6] L.S. Wong, R. Hashim, F.H. Alis, A review on experimental investigations of peat stabilization of paper, Australian Journal of Basic and Applied Sciences, 3(4), 35373552 (2009)

[7] World Business Council for Sustainable Development, International Energy Agency, Cement Technology Roadmap 2009, (2009)

[8] Food and agricultural commodities production of paper, (2012) 
[9] S.C. Lee, M. Mariattis, The effect of bagasse fibers obtained (from rind and pith component) on the properties of unsaturated polyester composites of paper, Materials Letters, 62(16), 2253-2256 (2008)

[10] A. Sales, S.A. Limas, Use of Brazilian sugarcane bagasse ash in concrete as sand replacement of paper, Waste Management, 30(6), 1114-1122 (2010)

[11] American Society of Testing Materials, Annual Book of ASTM Standards, Section Four: Construction, 04.08, (2000)

[12] S. Noto, Peat Engineering Handbook, Civil Engineering Research Institute, Hokkaido Development Agency, Japan. 1-35 (1991)

[13] S. Hamamoto, Effects of moisture content and shrinkage on soil-thermal properties for peat soils in Japan, International Conference on Sustainable Built Environment, Kandy, (2010)

[14] H. Hayashi, S. Nishimoto, M. Takahashis, Field performance of PVD combined with reinforced embankment on peaty ground of paper, Soils and Foundation, Japanese Geotechnical Society, 51(1), 191-201, (2011)

[15] ASTM-D4609s, Standard Guide for Evaluating Effectiveness of Admixtures for SoilStabilization of paper, American Society for Testing and Materials Standards, Pennsylvania, (2005)

[16] G.C. Isaia, A.L.G. Gastaldini, R. Moraess, Physical and pozzolanic action of mineral additions on the mechanical strength of high-performance concrete of paper, Cement and Concrete Composites, 25(1), 69-76 (2003)

[17] L.S. Wong, R. Hashim, F. Alis, Utilization of sodium bentonite to maximize the filler and pozzolanic effects of stabilized peat of paper, Engineering Geology, 152(1), 56-66 (2013)

[18] EuroSoilStab, Development of Design and Construction Methods to Stabilize Soft Organic Soils, Design Guide Soft Soil Stabilization, Project No. BE 96-3177, Industrial and Materials Technologies Programme, European Commission, (2002)

[19] F.O. Allu, Ramboll, Mass Stabilization Manual, Orimattila, Findand, (2005) 